\title{
Prevalence of Tobacco and Alcohol Consumption among Fishermen in Udupi Taluk, Karnataka, India: a Cross-Sectional Study
}

\author{
Prasad Pramod Rane ${ }^{1}$, Prakash Narayanan $^{2}$,VS Binu ${ }^{3}$, Bhaskaran Unnikrishnan**
}

\begin{abstract}
Background: Stress associated with fishing is known to trigger consumption of alcohol and tobacco among fishermen. This study aimed to assess the prevalence of tobacco and alcohol consumption among fishermen in Udupi Taluk in the state of Karnataka, India, and to study associations with health status and job stress. Materials and Methods: The study was conducted among 825 fishermen in Udupi Taluk of Karnataka between January-June 2015, using a two stage cluster sampling procedure. Associations between variables of interest were assessed using multivariable analysis and logistic regression models. Results: The prevalences of consumption of tobacco, alcohol and either of these substances were $64.2 \%, 45.6 \%$ and $86.9 \%$ respectively. There was a positive association between alcohol and any form of tobacco consumption with income but none with respondent's job stress and health status. Conclusions: Our study concluded that fishermen with poor health status are seen more among tobacco and alcohol users.
\end{abstract}

Keywords: Alcohol - fishermen - job stress - health status - tobacco

Asian Pac J Cancer Prev, 17 (4), 1733-1737

\section{Introduction}

Tobacco and alcohol consumption is considered as one of the major public health challenges. Globally approximately 190 million people consume tobacco or alcohol for recreational purposes or to relieve stress (Ramakrishna et al., 2006). Consumption rates of alcohol and tobacco in India are relatively high, with an estimated 275 million adults consuming tobacco in different consumption patterns (Kaur and Jain, 2011) and 70 million regular alcohol consumers, excluding additional millions of social drinkers (Mohan et al., 2011). Consequences of alcoholism include social issues such as general malfunctioning and social isolations, as well as physical problems including liver failure, esophageal bleeding, dementia and if unchecked multi-organ failure and ultimately death (Mohan et al., 2011).

The tobacco problem in India is complex due to the wide availability of different types of smoking, smokeless tobacco and diverse patterns of tobacco consumption (Sinha, 2006). Annually in India there are about 12 million cases of preventable tobacco related diseases (Soni and Raut, 2012). Tobacco consumption is one of the risk factor for cardiovascular diseases (CVDs), which is responsible for the highest global mortality (World Health Organisation, 2014). Pulmonary diseases associated with tobacco use include lung cancer and
Chronic Obstructive Pulmonary Disease (COPD) which leads to respiratory crippling and premature death (World Health Organisation, 2014). Beedi and cigarette smoking have been identified as a major risk factor for all type of cancers. India has the highest number of oral cancer cases in the world, it constitutes $12 \%$ of all cancers among men and $8 \%$ of all cancers among women. Oral cancer is largely contributed to high user rate of smoking and smokeless tobacco products (Soni and Raut, 2012).

Udupi is the coastal district located in Karnataka state of south India, sea-fishing is one of the main occupations of people (Jacob et al., 2013). Due to the dangers related to their job, their job related stress levels are generally perceived to be relatively high, which may lead to an increased rate of alcohol and tobacco consumption. Very few studies have been carried out that focuses on the health status of fishermen. This study aimed to assess the prevalence of consumption of tobacco and alcohol among fishermen and to find out the association between their health status, job stress and alcohol and tobacco consumption.

\section{Materials and Methods}

A descriptive cross sectional study was conducted during January to June 2015 among the fishermen to assess the prevalence of tobacco and alcohol consumption and 
their association with job stress and health status.

The sample size of 825 was calculated using a formula for estimation of proportion by relative precision, considering $95 \% \mathrm{CI}$ and $8 \%$ relative precision, and $63.4 \%$ prevalence of tobacco use (Bhondve et al., 2013). The study participants were the fishermen from the Udupi Taluk. It included all the participants aged above 18 years of age who gave written consent and excluded those who were under the influence of alcohol.

The list of fishing villages within Udupi Taluk were obtained from the District fishery office, Udupi. A household survey was conducted by using two stage cluster sampling method. In the first stage, 14 villages out of 34 villages were randomly selected. The sample size for each cluster (village) was assigned using PPS (probability proportionate to size) method. In the second stage, required number of households were selected using systematic random sampling approach. A total of 825 households were selected and one eligible respondent from each household were chosen for interview. If the subject was not available at home, three more visits were made to the house on a later date.

A pre-tested semi-structured questionnaire was used to capture information on background characteristics, tobacco and alcohol consumption, and health status. The assessments of job stress were performed using ISMA (International Stress Management Association) questionnaire (ISMA, 2013) which has been modified to suit the study population and content validity was done. For job stress, a score was calculated based on responses to a set of standardized questions. The questionnaire was framed in English, translated into Kannada and back translated into English and administered to the participants by the researcher. Ethical clearance for the study was obtained from the Institutional Ethics Committee, Kasturba Medical College (Manipal University) Manipal.

The data was analyzed using statistical software SPSS version 15 . Simple descriptive analysis was done to explore the socio-demographic profile, prevalence of tobacco and prevalence of alcohol use among the respondent. Sociodemographic information was categorized and described using frequencies and proportion. Multivariable analysis using Logistic regression was employed to assess the association between the various independent factors such as socio-demographic profile, job stress and the health status of the fishermen with alcohol consumption and usage of any form of tobacco product. Odds ratios with their $95 \% \mathrm{CI}$ and p-values were stated. The independent variables that has shown a statistical significance of less than 0.15 in univariate analysis were considered for multivariable logistic regression modeling.

\section{Results}

A total of 825 fishermen participated in the study Among them, $35.4 \%$ of participants belonged to the age group between $29-38$ years, $89.5 \%$ of participants were Hindus $.85 .2 \%$, were ever married. And only $14.8 \%$ of participants were unmarried. $35.5 \%$ had a monthly income of up to Rs.6000. $45.0 \%$ of participants attained the primary level of education. (Table 1).
The study showed that the use of tobacco in any form among participants were observed to be $64.2 \%$. With 95\% CI (61- $67 \%)$. Among the tobacco user in any form, $30 \%$ of participants had the habit of smoking tobacco, $22.55 \%$ of participants had the habit of using smokeless tobacco and $11.63 \%$ of participants had the habit of using both smoking and smokeless tobacco. The prevalence of alcohol consumption among participants was observed to be $45.6 \%$ with $95 \%$ CI (42-48\%). Among them $22.67 \%$ of participants reported to use only alcohol while $22.90 \%$ of participants had the habit of using both tobacco and alcohol.

The prevalence of any substance use among participant were observed to be $86.9 \%$ with $95 \%$ CI (84-89\%). Among substance use, $20.46 \%$ of participants had the habit of only smoking tobacco, $14.30 \%$ participants had the habit of using only smokeless tobacco, $20.70 \%$ of participants had the habit of only drinking alcohol, $6.66 \%$ of participants had the habit of using smoking and smokeless tobacco, $8.24 \%$ participants had the habit of using both smokeless tobacco and alcohol, $4.96 \%$ of participants had the habit of smoking, smokeless tobacco and alcohol.

Study showed almost three quarter of participants, $72.7 \%$ were more likely to experience stress related ill health; either mental, physical or both. Only $4.1 \%$ participants were very prone to stress showing characteristics that are creating un-healthy behavior and they were also more likely to experience stress and stress related illness (e.g. diabetes, irritable bowel, migraine, back and neck pain, high blood pressure, heart disease/stroke, mental ill health)

Among the participants $85.0 \%$ of participants perceived their health status as satisfactory, $8.0 \%$ participants perceived their health status as bad and $7.0 \%$ participants perceived their health status as good or excellent. Demographic data such as the respondent's monthly family income and education level were carried forward into multivariable logistic regression models to look for associations with any form of tobacco consumption. It showed that there was a significant

Table 1. Distribution of the Respondents According to the Socio-Demographic Characteristics, $(n=825)$

\begin{tabular}{ccc}
\hline Variables & Category & Frequency n (\%) \\
\hline Age & $19-28$ & $135(16.4 \%)$ \\
(in years) & $29-38$ & $292(35.4 \%)$ \\
& $39-48$ & $215(26.1 \%)$ \\
Religion & 49 and above & $183(22.2 \%)$ \\
& Hindu & $738(89.5 \%)$ \\
Marital status & Muslim & $71(8.6 \%)$ \\
& Christian & $16(1.9 \%)$ \\
Monthly family & Ever married & $703(85.2 \%)$ \\
income (in Rupee) & Unmarried & $122(14.8 \%)$ \\
& Up to 6000 & $293(35.5 \%)$ \\
& 6001-9000 & $288(34.9 \%)$ \\
& 10001 and above & $135(16.4 \%)$ \\
& Illiterate & $239(29.0 \%)$ \\
& Literate but no & $39(4.7 \%)$ \\
Educational status & formal education & $371(45.0 \%)$ \\
& Primary & $176(21.3 \%)$ \\
\hline
\end{tabular}


Table 2. Univariate and Multivariable Logistic Regression for the Association between Independent Factors and any Form of Tobacco Consumption, $(\mathbf{n}=\mathbf{8 2 5})$

\begin{tabular}{|c|c|c|c|c|c|c|c|}
\hline \multirow[b]{2}{*}{ Variables } & \multirow[b]{2}{*}{ Category } & \multicolumn{2}{|c|}{ Tobacco consumption } & \multirow[b]{2}{*}{$\begin{array}{l}\text { unadjusted OR } \\
\text { (95\%) CI }\end{array}$} & \multirow[b]{2}{*}{$\begin{array}{c}\mathrm{P} \\
\text { value }\end{array}$} & \multirow[b]{2}{*}{$\begin{array}{l}\text { Adjusted OR } \\
(95 \%) \text { CI }\end{array}$} & \multirow[b]{2}{*}{$\mathrm{P}$ value } \\
\hline & & Yes n $(\%)$ & No n $(\%)$ & & & & \\
\hline \multirow{4}{*}{$\begin{array}{l}\text { Age } \\
\text { (in years) }\end{array}$} & $19-28$ & $86(63.7 \%)$ & $49(36.3 \%)$ & 1 [Reference] & & & \\
\hline & $29-38$ & $173(59.2 \%)$ & $119(40.8 \%)$ & $0.82[0.54,1.26]$ & 0.38 & & \\
\hline & $39-48$ & $152(70.7 \%)$ & $63(29.3 \%)$ & $1.37[0.87,2.17]$ & 0.17 & & \\
\hline & 49 and above & $119(65.0 \%)$ & $64(35.0 \%)$ & $1.05[0.66,1.68]$ & 0.80 & & \\
\hline \multirow{3}{*}{ Religion } & Hindu & $480(65.0 \%)$ & $258(35.0 \%)$ & 1 [Reference] & & & \\
\hline & Muslim & $42(59.2 \%)$ & $29(40.8 \%)$ & $0.77[0.47,1.27]$ & 0.32 & 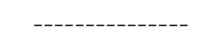 & \\
\hline & Christian & $8(50.0 \%)$ & $8(50.0 \%)$ & $0.53[0.19,1.44]$ & 0.22 & & \\
\hline \multirow{7}{*}{$\begin{array}{l}\text { Marital } \\
\text { status } \\
\text { Monthly } \\
\text { family } \\
\text { income } \\
\text { (in Rupee) }\end{array}$} & Married & $459(65.3 \%)$ & $244(34.7 \%)$ & $1.35[0.91,1.99]$ & 0.13 & $1.23[0.81,1.85]$ & 0.32 \\
\hline & Unmarried & $71(58.2 \%)$ & $51(41.8 \%)$ & 1 [Reference] & & 1 [Reference] & \\
\hline & Up to 6000 & $204(69.6 \%)$ & $89(30.4 \%)$ & 1 [Reference] & & 1 [Reference] & \\
\hline & $6001-9000$ & $191(66.3 \%)$ & $97(33.7 \%)$ & $0.85[0.60,1.21]$ & 0.39 & $0.85[0.59,1.21]$ & 0.37 \\
\hline & $9001-10000$ & $79(58.5 \%)$ & $56(41.5 \%)$ & $0.61[0.40,0.94]$ & 0.02 & $0.63[0.41,0.98]$ & 0.04 \\
\hline & 10001 and above & $56(51.4 \%)$ & $53(48.6 \%)$ & $0.46[0.29,0.72]$ & $<0.01$ & $0.48[0.30,0.76]$ & $<0.01$ \\
\hline & Illiterate & $160(66.9 \%)$ & $79(33.1 \%)$ & $1.50[1.00,2.24]$ & 0.04 & $1.24[0.81,1.90]$ & 0.31 \\
\hline \multirow{3}{*}{$\begin{array}{l}\text { Educational } \\
\text { status }\end{array}$} & $\begin{array}{l}\text { Literate but no } \\
\text { formal education }\end{array}$ & $27(69.2 \%)$ & $12(30.8 \%)$ & $1.67[0.79,3.51]$ & 0.17 & $1.37[0.64,2.94]$ & 0.40 \\
\hline & Primary & $242(65.2 \%)$ & $129(34.8 \%)$ & $1.39[0.96,2.01]$ & 0.07 & $1.24[0.85,1.82]$ & 0.25 \\
\hline & Secondary & $101(57.4 \%)$ & $75(42.6 \%)$ & 1 [Reference] & & 1 [Reference] & \\
\hline \multirow{3}{*}{ Job stress } & Least likely to stress & $125(65.4 \%)$ & $66(34.6 \%)$ & 1 [Reference] & & & \\
\hline & More likely to stress & $383(63.8 \%)$ & $217(36.2 \%)$ & $0.93[0.66,1.31]$ & 0.68 & & \\
\hline & Most prone to stress & $22(64.7 \%)$ & $12(35.3 \%)$ & $0.96[0.45,2.07]$ & 0.93 & & \\
\hline \multirow{3}{*}{$\begin{array}{l}\text { Health } \\
\text { status }\end{array}$} & Excellent/good & $41(70.7 \%)$ & $17(29.3 \%)$ & 1 [Reference] & & & \\
\hline & Satisfactory & $437(62.3 \%)$ & $264(37.7 \%)$ & $0.68[0.38,1.23]$ & 0.20 & & \\
\hline & $\mathrm{Bad}$ & $52(78.8 \%)$ & $14(21.2 \%)$ & $1.54[0.68,3.48]$ & 0.30 & & \\
\hline
\end{tabular}

Table 3. Univariate and Multivariable Logistic Regression for the Association between Independent Factors and any Form of Alcohol Consumption $(n=825)$

\begin{tabular}{|c|c|c|c|c|c|c|c|}
\hline Variables & Category & $\begin{array}{c}\text { Alcoholic n } \\
(\%)\end{array}$ & $\begin{array}{c}\text { Nonalcoholic } \\
\mathrm{n}(\%)\end{array}$ & $\begin{array}{c}\text { Unadjusted OR } \\
(95 \%) \mathrm{CI} \\
\end{array}$ & $P$ value & $\begin{array}{l}\text { Adjusted OR } \\
(95 \%) \mathrm{CI} \\
\end{array}$ & $\mathrm{P}$ value \\
\hline \multirow{4}{*}{$\begin{array}{l}\text { Age } \\
\text { (in years) }\end{array}$} & $19-28$ & $51(37.8 \%)$ & $84(62.2 \%)$ & $1[$ Reference $]$ & & 1 [Reference] & \\
\hline & $29-38$ & $135(46.2 \%)$ & $157(53.8 \%)$ & $0.70[0.46,1.07]$ & 0.10 & $0.75[0.48,1.18]$ & 0.21 \\
\hline & $39-48$ & $96(44.7 \%)$ & $119(55.3 \%)$ & $0.75[0.48,1.16]$ & 0.20 & $0.82[0.51,1.34]$ & 0.44 \\
\hline & 49 and above & $94(51.4 \%)$ & $89(48.6 \%)$ & $0.57[0.36,0.90]$ & 0.01 & $0.64[0.38,1.06]$ & 0.08 \\
\hline \multirow{3}{*}{ Religion } & Hindu & $335(45.4 \%)$ & $403(54.6 \%)$ & $1[$ Reference $]$ & & & \\
\hline & Muslim & $32(45.1 \%)$ & $39(54.9 \%)$ & $1.01[0.62,1.65]$ & 0.95 & & \\
\hline & Christian & $9(56.2 \%)$ & $7(43.8 \%)$ & $0.64[0.23,1.75]$ & 0.39 & & \\
\hline \multirow{2}{*}{ Marital status } & Ever married & $328(46.7 \%)$ & $375(53.3 \%)$ & $0.74[0.50,1.09]$ & 0.13 & $0.91[0.65,1.27]$ & 0.72 \\
\hline & Never married & $48(39.3 \%)$ & $74(60.7 \%)$ & $1[$ Reference $]$ & & $1[$ Reference $]$ & \\
\hline \multirow{4}{*}{$\begin{array}{l}\text { Monthly } \\
\text { family income } \\
\text { (in Rupee) }\end{array}$} & Up to 6000 & $128(43.7 \%)$ & $165(56.3 \%)$ & $1[$ Reference $]$ & & $1[$ Reference $]$ & \\
\hline & $6001-9000$ & $130(45.1 \%)$ & $158(54.9 \%)$ & $0.94[0.68,1.30]$ & 0.72 & $0.91[0.65,1.27]$ & 0.60 \\
\hline & $9001-10000$ & $60(44.4 \%)$ & $75(55.6 \%)$ & $0.97[0.64,1.46]$ & 0.88 & $0.88[0.57,1.34]$ & 0.55 \\
\hline & 10001 and above & $58(53.2 \%)$ & $51(46.8 \%)$ & $0.68[0.43,1.06]$ & 0.08 & $0.62[0.39,0.97]$ & 0.03 \\
\hline \multirow{4}{*}{$\begin{array}{l}\text { Educational } \\
\text { status }\end{array}$} & Illiterate & $120(50.2 \%)$ & $119(49.8 \%)$ & $0.70[0.47,1.04]$ & 0.07 & $0.70[0.46,1.07]$ & 0.10 \\
\hline & $\begin{array}{l}\text { Literate but no } \\
\text { formal education }\end{array}$ & $20(51.3 \%)$ & $19(48.7 \%)$ & $0.67[0.33,1.35]$ & 0.26 & $0.65[0.31,1.33]$ & 0.24 \\
\hline & Primary & $163(43.9 \%)$ & $208(56.1 \%)$ & $0.90[0.62,1.30]$ & 0.58 & $0.88[0.60,1.28]$ & 0.52 \\
\hline & Secondary & $73(41.5 \%)$ & $103(58.5 \%)$ & $1[$ Reference] & & $1[$ Reference $]$ & \\
\hline \multirow{3}{*}{ Job stress } & Least likely to stress & $95(49.7 \%)$ & $96(50.3 \%)$ & $1[$ Reference $]$ & & & \\
\hline & More likely to stress & $260(43.3 \%)$ & $340(56.7 \%)$ & $1.29[0.93,1.79]$ & 0.12 & & \\
\hline & Most prone to stress & $21(61.8 \%)$ & $13(38.2 \%)$ & $0.61[0.29,1.29]$ & 0.19 & & \\
\hline \multirow{3}{*}{ Health status } & Excellent/good & $23(39.7 \%)$ & $35(60.3 \%)$ & $1[$ Reference $]$ & & & \\
\hline & Satisfactory & $322(45.9 \%)$ & $379(54.1 \%)$ & $0.77[0.44,1.33]$ & 0.35 & & \\
\hline & $\mathrm{Bad}$ & $31(47.0 \%)$ & $35(53.0 \%)$ & $0.74[0.36,1.51]$ & 0.41 & & \\
\hline
\end{tabular}

association of consumption of any form of tobacco and independent factor such as monthly family income adjusted to education level with odds of (OR (0.48);
95\%CI (0.30, 0.76); $\mathrm{p}=0.002)$ (Table 2).

Demographic data such as the respondent's age, marital status, monthly family income and education level 
were carried forward into multivariable logistic regression models to look for associations with alcohol consumption. It showed that there was a significant association of alcohol consumption and independent factor such as monthly family income adjusted to age, marital status and education level with odds of (OR (0.61); 95\%CI (0.39, 0.97); $\mathrm{p}=0.03$ ) (Table 3).

\section{Discussion}

In this study majority of the participants were in their productive age group of 19-48 years, literate and were married. Globally many studies showed that alcohol and tobacco intake was very prevalent among fishermen (Lawrie et al., 2004; Bhondve et al., 2013). This study also showed that tobacco and alcohol consumption is very much prevalent among young fishermen. A study done in West Bengal among the fishermen showed the same result that smoking, smokeless tobacco and alcohol consumption were common habit among young fishermen (Panigrahi and Bakshi, 2014).

Overall prevalence of tobacco use among fishermen in any form in the present study was $64.2 \%$. This prevalence is comparable with other studies conducted among fishermen in India and abroad. A study done in Mumbai reported a prevalence for tobacco consumption as $73.4 \%$ among the fishermen (Bharadva et al., 2014). Usually fishermen consume tobacco as it helps them in relieving the feelings of stress at work place. In our study $20.46 \%$ of participants had the habit of using tobacco in the form of smoking alone. Other studies also showed a higher prevalence of smoking tobacco among fishermen (Lawrie et al., 2004; ElSaadawy et al., 2014). In India smoking is prohibited at work place, because of that the fishermen were not able to smoke at work place and this might have resulted in reduced consumption of smoking tobacco in India as compared to fishermen in other countries. In our study $14.30 \%$ of the participants were using smokeless tobacco, wherein the prevalence was five times more in Pakistani fishermen, the reason may be because of cheaper price, easy availability and low levels of education (Patoli et al., 2015).

Our study found $45.6 \%$ alcohol consumption among the fishermen wherein other studies from India and abroad showed higher prevalence of alcohol consumption i.e., $63.4 \%$ and $80.6 \%$ respectively (Lawrie et al., 2004; Bhondve et al., 2013). This could be because of cultural variations between region to region and levels of affordability to alcohol. The prevalence of any sort of substance use (some kind of addiction) was $86.9 \%$ in our study. Similar result was observed in a study carried out among the fishermen in Mumbai, which reported that $81.6 \%$ of fishermen had some kind of addiction to any one sort of substances (Bhondve et al., 2013). The prevalence was more because most of the fishermen might have prolonged work hours or may be due to the belief that tobacco and alcohol consumption increases their work productivity. Some respondents commended that they consume tobacco and alcohol to get relieved out of tiredness due to overwork.

In our study, nearly three quarter $(72.7 \%)$ of participants were more likely to have experienced stress related to ill health. Similar results were found in two other studies conducted in India, i.e., $62.1 \%$ and $67.8 \%$ respectively (Jacob et al., 2013; Bhondve et al., 2013). In the present study the association of stress and consumption of tobacco and alcohol was not found to be statistically significant. Our results are comparable to another study conducted among bank employees in urban Pudducherry, India (Kumar and Sundaram, 2014).Similar result were found among Law enforcement personnel in Mangalore, India (R Priyanka et al., 2016). Usually the use of tobacco and alcohol consumption are initiated before joining the occupation, the impact of stress can have an effect on the intensity of consumption of tobacco and alcohol but may not be on their status (Azagba and Sharaf, 2011). Fishing is an occupation which is unorganized and very risky, it might be a reason for job stress or it could be because of extended hours of works in the night thereby the adverse effects of sleep deprivation or could be because of over work.

In our study, multivariable regression analysis showed that there was a significant association between monthly family income and tobacco consumption i.e., tobacco consumption was more among fishermen who had higher monthly family income. The results of our study were similar with a study which was done among diamond polishing workers of Surat city in India where tobacco consumption was more among those who belong to high socio-economic class (Bharadva et al., 2014). A cross sectional survey conducted among 24 Indian states found that the tobacco consumption was more among higher income group (Agarwal et al., 2013), this might be because of easy accessibility and affordability to smoking and smokeless tobacco. The lifestyle factors driving to have an access to these tobacco products could be cultural acceptances or could be imitating the peer group. Participants who consumed tobacco products responded that they were consuming these substances for fun.

Our study also revealed that alcohol consumption was very high among higher monthly family income group. Possibly high income persons have increased capacity to access and afford alcohol. A study done among police personnel at Bhubaneshwar in India showed that the majority of participants were consuming alcohol and were belonging to higher monthly income group (Bhumij and Jayakrishnan, 2015). Similar result was found in the study from Taiwan which showed that the alcohol consumption rate was high among those with better economic status (Guo et al.,2013). A study done in urban Tanzania reported that alcohol consumption was higher among people belonging to higher socio economic class (Mbatia et al., 2009). Self-reporting on questions related to job stress and health status might have induced some bias in our study.

In conclusion, In the present study, fishermen with poor health status were more among tobacco and alcohol users. Fishermen's monthly family income was associated with use of any form of tobacco and alcohol. Awareness programs should be implemented among the Udupi fishermen community to educate them about the health risks associated with alcohol and tobacco consumption. This might play an important role in the prevention of 
Prevalence of Tobacco and Alcohol Consumption among Fishermen in Udupi, Karnataka, India: a Cross-Sectional Study.

tobacco and alcohol associated health problems among this target population. In addition, taxes on tobacco and alcohol products should be raised and multipronged approaches should be undertaken for the cessation of use of tobacco and alcohol. There is a need for more research among the fishermen community to assess their health status and compare it with other communities that experience less work related stress.

\section{References}

Agrawal S, Karan A, Selvaraj S, et al (2013). Socio-economic patterning of tobacco use in Indian states. Int J Tuberculosis Lung Disease, 17, 1110.

Azagba S, Sharaf MF (2011). The effect of job stress on smoking and alcohol consumption. Health Economics Rev, 1, 1-14.

Bharadva NA, Gamit CL, Mansuri BM, et al (2014). Prevalence of various forms of tobacco use and factors related with it in diamond cutting and polishing workers of Surat City, India. Int J Interdiscip Multidicip Stud, 1, 27-32.

Bhondve A, Kasbe A, Mahajan H, et al (2013). Assessment of job satisfaction among fishermen in southern-east costal area of mumbai, India. General Med, 2, 65-74.

Bhumij N, jayakrishnan K (2015). Effectiveness of Brief intervention in alcohol use among police personnel in Bhubaneswar, Int J Public Mental Health Neurosciences, 2, 19-23.

ElSaadawy M, Soliman N, ElTayeb IM, et al (2014). Some occupational health hazards among fishermen in Alexandria city. Gaziantep Med J, 20, 71-78.

Guo SE, Huang TJ, Huang JC, et al (2013). Alcohol, betel-nut and cigarette consumption are negatively associated with health promoting behaviors in Taiwan: a cross-sectional study. BMC Public Health, 13, 257.

ISMA. (2013). Stress questionnaire. accessed november 22,2014 from http://www.isma.org.uk/wp-content/uploads/2013/08/ Stress-Questionnaire.pdf

Jacob JM, George LS,Savitha (2013). Job stress and coping among fishermen. Nitte University $J$ Health Science, $\mathbf{3}$, 93-96.

Kaur J, Jain D (2011). Tobacco control policies in India: implementation and challenges. Indian J Public Health, $\mathbf{5 5}, 220$.

Kumar SG, Sundaram ND (2014). Prevalence of stress level among Bank employees in urban Puducherry, India. Industrial Psychiatry J, 23, 15.

Lawrie T, Matheson C, Ritchie L, et al (2004). The health and lifestyle of Scottish fishermen: A need for health promotion. Health Education Res, 19, 373-79.

Mbatia J, Jenkins R, Singleton N, et al (2009). Prevalence of alcohol consumption and hazardous drinking, tobacco and drug use in urban Tanzania, and their associated risk factors. Int J Environmental Res Public Health, 6, 1991-2006.

Mohan D, Chopra A, Ray R,et al (2001). Alcohol consumption in India:Across-sectional study. Surveys of drinking patterns and problems in seven developing countries. Geneva: World Health Organization, 103-14.

Panigrahi AK , Bakshi A. (2014). a study on profile of fishing community of the river side villages of river churni, nadia, west bengal with special reference to socio-economic and technological appraisal of fishermen. Int J Res Applied, Nat Soc Sci, 2, 97-102.

Patoli S, Jabeen N, Masood RT, et al (2015). Socioeconomic status and smokeless tobacco consumption in fishermen community of a coastal area of Karachi. Annals Abbasi Shaheed Hospital Karachi Medical Dental College, 20, 34-39.

Priyanka R, Rao A, Rajesh G, et al (2016). Work-associated Stress and Nicotine Dependence among Law Enforcement Personnel in Mangalore, India. Asian Pac J Cancer Prev, 17, 829-33.

Ramakrishna GS, Sankara Sarma P, Thankappan KR (2006). Tobacco use among medical students in Orissa. National Med J India, 18, 285-9.

Sinha DN (2006). Tobacco control in india:india global youth tobacco survey \& global school personnel survey. Indian $J$ Dental Res, 18, 2-5.

Soni P, Raut DK (2012). Prevalence and pattern of tobacco consumption in India. Int Res J Social Sci, 1, 36-43.

World Health Organisation. (2014). Global status report on alcohol and health 2014. world health organisation. Retrieved from http://www.who.int/substance_abuse/ publications/global_alcohol_report/msbgsruprofiles.pdf 